\title{
Gamify Online Courses With Tools Built Into Your Learning Management System (LMS) to Enhance Self-Determined and Active Learning
}

\author{
Cheng-Chia (Brian) Chen, ChingChih (Kathy) Huang, Michele Gribbins, and Karen Swan \\ University of Illinois at Springfield
}

\begin{abstract}
"Gamified" active learning has been shown to increase students' academic performance and engagement and help them make more social connections than standard course settings. However, the costs to use an educational game design with efficient delivery of the game/course plan can be problematic. Our first objective was to evaluate the effectiveness of gamification by using existing techniques (e.g., simple HTML-based games) and readily available collaborative tools (e.g., wikis) from a typical learning management system (LMS), such as Blackboard. Our second objective was to examine students' attitudes toward gamification (e.g., perceived usefulness). An online survey was given to 80 graduate students who took an entry-level biostatistics course from 2015 to 2017 at a midwestern university in the United States. Our study was conducted using an experimental group (class with implementation of gamification) and control group (class without implementation of gamified activities) that were randomly selected from graduate-level statistics courses. A Welch's independent $t$-test revealed a significant difference $(p<.001)$ in the mean exam scores of the experimental and control groups. The difference favored classes with gamification. The findings suggest that using built-in LMS tools to design gamified learning activities can enhance students' academic performance and the competencies gained, as well as provide more diversified learning methods and motivation, and offer easy modifications for different learning needs.
\end{abstract}

Keywords: gamification, game-based learning, online learning, LMS, engagement

Chen, C.-C., Huang, C., Gribbins, M., \& Swan, K. (2018). Gamify online courses with tools built into your learning management system (LMS) to enhance self-determined and active learning. Online Learning, 22(3), 41-54. doi:10.24059/olj.v22i3.1466

\section{Gamify Online Courses With Tools Built Into Your Learning Management System (LMS) to Enhance Self-Determined and Active Learning}

Gamification and game-based learning have been the buzzwords in a variety of disciplines, including education, math, statistics, business, computer science, and healthrelated professions (Dicheva et al., 2015; Hamari, Koivisto, \& Sarsa, 2014; Seaborn \& Fels, 2015). The definition of "gamification" has been quite challenging to pin down because of multiple applications in a variety of formats. Thus, it might be easier to understand the 
definition of "game" first before educators arrive at definition of gamification. According to game/gamification theory literature, game can be defined as "a system in which players engage in an artificial conflict, defined by rules, that results in a quantifiable outcome" (Salen \& Zimmerman, 2004, pp. 80-81). A standard definition of gamification was proposed by Seaborn and Fels (2015) that "gamification is the intentional use of game elements for a gameful experience of non-game tasks and contexts" (p. 17). In practice, gamification in education has been used with gamified designs in an instructional system that supports nongame activities to increase student engagement and learning motivation in a fun atmosphere.

The prominence of the digital game medium in popular culture and personal entertainment has increased interest in the study of the effectiveness of gamification in enhancing academic performance and educational relevance in the digital age (Seaborn et al., 2015). More frequent and comprehensive implementation of gamification and gamified activities has been increasingly recognized in business and education (Hamari et al., 2014; Seaborn et al., 2015; Yildirim, 2017). The concept of gamified learning extends educators' application of traditional teaching strategies and provides an attractive method that may facilitate students' engagement and increase their academic performance.

The applications of gamification for online courses have been limited. Gamified active learning could increase student engagement, create enthusiasm, provide instant feedback, and make more social connections than standard online course settings (Seaborn et al., 2015). However, the costs to use an educational game design with effective delivery of the game plans and course contents can be problematic, especially for instructors without extensive knowledge in computerized gaming and/or a budget to create such environments (Kapp, 2012). Moreover, it can be difficult to find a good fit between the games on the market and course learning objectives. In addition, instructors may have insufficient resources and training in online teaching technology to even initiate game settings in online courses.

To take advantage of the possible benefits from gamification and overcome the above challenges in online learning environments, there is a strong need to develop innovative gamified activities based on the capabilities of the existing techniques (e.g., simple HTMLbased games) and readily available collaborative tools (e.g., wikis) from the most commonly used learning management systems (LMS), such as Blackboard, Canvas, Moodle, or D2L. To contribute to the present knowledge of gamification in online learning and higher education, our research aims were (1) to investigate whether gamified activities for online graduate-level statistics courses can improve students' academic performance and perceived statistical competency, (2) to explore whether the implementation of gamification can enhance online students' engagement, and (3) to examine students' attitudes (e.g., perceived usefulness of gamified activities in reviewing class materials) toward gamified activities in an online learning environment.

\section{Theoretical Framework}

The theoretical framework was inspired by literature reviews of gamification studies and self-determination theory (SDT) (Deterding, 2011; Dicheva et al., 2015; Hamari et al., 2014; Kim et al., 2017; O’Donnell et al., 2017; Seaborn et al., 2015; Simões, Redondo, \& Vilas, 2013; Wilson et al., 2009). This integrated framework was used to design the online gamified activities and guide our study. Based on the literature, gamification elements (e.g., feedback, challenge, rewards, and objectives) may contribute to improved academic performance. Moreover, the "competence" concept from the SDT (i.e., the need to feel that one's behavior is effective) that is theorized as increasing intrinsic learning motivation was evaluated in the present study in the sense that we investigated whether the competence gained from an online course can be enhanced when students have opportunities to learn skills and be challenged in 
proper ways through gaming, as well as receive informational and positive feedback (Forde, Mekler, \& Opwis, 2015; Ryan \& Deci, 2000).

\section{Methods}

This study employed an experimental research design with the random assignments of participants to the experimental and control groups. We examined students' academic performance, perceived competency in statistics, and perceived engagement before and after the implementation of gamified activities. Moreover, students' perceptions of the usefulness of gamified activities were observed.

Though several studies have argued that gamification could be a great teaching tool across multiple disciplines, challenges for effective implementation still exist. Due to different approaches in gamification applications based on the interests and needs of various fields, it is still quite challenging to provide successful online gamified environments to enhance academic performance and increase learning motivation and student engagement (Dicheva et al., 2015; Kapp, 2012). Therefore, we identified commonality among the fundamental elements of gamification based on gamification theories (Deterding et al., 2011; Kappen \& Nacke, 2013; Harari et al., 2014; Seaborn et al., 2015) and integrated them into the present study. The gamified activities included major key gamification elements (e.g., points, leaderboards, progression, status, levels, and rewards).

Two well-designed online educational games, "Concept Review Bingo" and "Jeopardy Exam Review," were implemented in a graduate-level statistics course. These online versions of bingo and Jeopardy games were designed using the wiki format that is usually a built-in feature in any LMS. A wiki is "an expandable collection of interlinked Web 'pages', a hypertext system for storing and information - a database, where each page is easily editable by any user with a form-capable Web Browser clients" (Leuf \& Cunningham, 2001, p. 14). In other words, a wiki can be a collaborative tool that allows students to create web contents (e.g., web pages, texts, and tables). For the present study, we used the built-in wiki setting in the LMS to create an editable contingency table (i.e., a 4 x 4 table [bingo] or a 6 x 5 table [Jeopardy]), where each cell contained a short essay or statistical calculation question.

One of the special characteristics of the gamified activities was to have students submit their answers in a game setting, such as online bingo or Jeopardy. Both gamified activities required players to provide their answers into a wiki-based table through an online course LMS. By default, only one student in a course could log in to edit the wiki table, while everyone else would have their access to the wiki table blocked until the student logged out. This mechanism created a natural first-come, first-choice environment, which fits the competition and challenge element in the gamification design. Most LMS companies provide some forms of wiki capabilities to higher education institutions.

"Concept Review Bingo" served to review key statistical concepts for exam preparation. The game consisted of 16 questions, which varied in difficulty. The questions were arranged in a $4 \times 4$ table, as illustrated in Figure 1. Each student was permitted to answer up to four of the questions in the table. Each correctly answered question earned the student one point of extra credit. However, if a student correctly answered four questions across a row, vertically in a column, or diagonally, the student earned a bingo. This resulted in double points for the activity. Because of the first-come, first-choice nature of wikis, students were motivated to submit their answers quickly to claim their questions. Once all 16 questions were answered, feedback was provided to the entire class. Table 1 summarizes the gamification components for "Concept Review Bingo." 
Gamify Online Courses With Tools Built Into Your Learning Management System (LMS)

to Enhance Self-Determined and Active Learning

Review Bingo: Descriptive Statistics

Created By Cheng-Chia B. Chen on Monday, January 22, 2018 5:20:17 PM CST

last modified by 8 Cheng-Chia B. Chen on Thursday, May 31, 2018 7:12:01 AM CDT

You must type your answers and name (at the same time)!!!

\begin{tabular}{|c|c|c|c|}
\hline $\begin{array}{l}\text { 1. Give examples of quantitative and } \\
\text { qualitative variables; discrete and } \\
\text { continuous variables; and determine } \\
\text { the appropriate measurement scale } \\
\text { for each. } \\
\text { Answer. }\end{array}$ & $\begin{array}{l}\text { 2. Give an example of descriptive } \\
\text { statistics. Give an example of } \\
\text { inferential statistics. } \\
\text { Answer: } \\
\text { Name: }\end{array}$ & $\begin{array}{l}\text { 3. Define stem and leaf plot and } \\
\text { construct a stem and leaf plot for the } \\
\text { following data. In addition, provide a } \\
\text { 5-number summary. } \\
12233051 \\
12273342 \\
18243648 \\
\text { Answer: } \\
\text { Name: }\end{array}$ & $\begin{array}{l}\text { 4. The Swiss physician H.C. Lombard } \\
\text { once compiled longevity data for } \\
\text { different professions. He used death } \\
\text { certificates that included name, age, } \\
\text { at death, and profession. He then } \\
\text { proceeded to compute the average } \\
\text { (mean) length of life for the different } \\
\text { professions, and he found that } \\
\text { students were lowest with a mean of } \\
\text { only } 20.7 \text { years! (Read "A Selection of } \\
\text { Selection Anomalies" by Wainere, } \\
\text { Palmer, and Bradlow in Chance, } \\
\text { Volume } 11, \text { No.2) Similar results would } \\
\text { be obtained if the same data were } \\
\text { collected today in the United States. } \\
\text { Please analyze the results: Is being a } \\
\text { student really more dangerous than } \\
\text { being a police officer, a taxicab driver, } \\
\text { or a postal employee? Explain. } \\
\text { Answer: } \\
\text { Name: }\end{array}$ \\
\hline $\begin{array}{l}\text { 5. What is the difference between a } \\
\text { discrete variable and a continuous } \\
\text { variable? } \\
\text { Answer: } \\
\text { Name: }\end{array}$ & $\begin{array}{l}\text { 6. What is the difference between a } \\
\text { population and a sample? } \\
\text { Answer: } \\
\text { Name: }\end{array}$ & $\begin{array}{l}\text { 7. Suppose we randomly select a } \\
\text { graduate class in the College of Public } \\
\text { Affairs and Administration to do a } \\
\text { survey on students' statistical skills } \\
\text { based on their statistics profiles. What } \\
\text { is a reasonable sample? What is a } \\
\text { reasonable population? Can } \\
\text { inferences be made to all UIS } \\
\text { students or all residents of Illinois? } \\
\text { Justify. } \\
\text { Answer: } \\
\text { Name: }\end{array}$ & $\begin{array}{l}\text { 8. What is a standard deviation? What } \\
\text { does the standard deviation tell you } \\
\text { about your data? } \\
\text { Answer: } \\
\text { Name: }\end{array}$ \\
\hline $\begin{array}{l}\text { 13. According to the week } 2 \text { lecture, } \\
\text { why divide by ( } n-1) \text { instead of by } n \\
\text { when we are calculating the sample } \\
\text { standard deviation? } \\
\text { Answer: } \\
\text { Name: }\end{array}$ & $\begin{array}{l}\text { 14. Provide the three distributional } \\
\text { shapes (normal, left-skewed, and } \\
\text { right-skewed) along with some of their } \\
\text { real-life examples. Describe the } \\
\text { relationships between mean, median, } \\
\text { and mode for each distribution. } \\
\text { Answer: } \\
\text { Name: }\end{array}$ & $\begin{array}{l}\text { 15. Define each of the following terms: } \\
\text { Biostatistics, Descriptive Statistics, } \\
\text { and Inferential Statistics. What is the } \\
\text { role of biostatistics in public health } \\
\text { research and program evaluation? } \\
\text { Answer: } \\
\text { Name: }\end{array}$ & $\begin{array}{l}\text { 16. An article in the New York Times } \\
\text { noted that the ZIP code of } 10021 \text { on } \\
\text { the Upper East Side of Manhattan is } \\
\text { being split into the three ZIP codes of } \\
10065,10021 \text {, and } 10075 \text { (in } \\
\text { geographic order from south to north) } \\
\text { The ZIP codes of } 11 \text { famous residents } \\
\text { (including Bill Cosby, spike Lee, and } \\
\text { Tom Wolfe) in the } 10021 \text { ZIP code will } \\
\text { have these ZIP codes after the } \\
\text { change: } 10065,10065,10065,10065 \text {, } \\
10065,10065,10021,10021,10075 \text {, } \\
10075,10075,10075,10075 \text {. What is } \\
\text { wrong with finding the mean and } \\
\text { standard deviation of these } 11 \text { ZIP } \\
\text { codes? } \\
\text { Answer: } \\
\text { Name: }\end{array}$ \\
\hline
\end{tabular}

Figure 1. Screenshot of "Concept Review Bingo." 
Table 1

Online "Concept Review Bingo" Gamification Elements and Design Principles

Elements of Gamification for "Concept Review Bingo"

Objectives

Competition \& Challenge

Feedback

Points, Rewards, \&

Leaderboards

Levels

Platform

Rules \& Customization

Storytelling, Theme, \&

Role-Playing

Replayability

\section{Implementation of the Element \& Design Principle}

The goals to review key statistical concepts for exam preparation.

Students compete to win extra credits and encounter a variety of challenges in the game settings.

The feedback (i.e., detailed answers and/or explanation videos) is given after students have answered all questions (an example of shortened feedback cycles).

Each selected-response question answered correctly is worth one bonus point. If a student has all four correct answers covered diagonally, across a row, and vertically in a column, the student will get a doubled award, which is worth 8 points $(4 \times 2=8)$.

Different levels (difficulties) of questions are created.

Wikis (i.e., a website developed collaboratively by a community of players, allowing any player to add and edit content).

Game mechanics and adaptive mechanisms to meet the players' skill levels and needs.

N/A

N/A

Similar to the game mechanics of the long-running Jeopardy television show, the online "Jeopardy Exam Review" consisted of six categories of topics. Each category included five questions ranging in difficulty (see Figure 2). The "dollar" value earned with each correct answer increased as the question's difficulty increased (see Figure 3). After the end of the "Jeopardy Exam Review" game, we provided instructional videos for each question with thorough explanations for the gamified questions (see Figure 4). The "Jeopardy Exam Review" demonstrates different game mechanics and structures than the "Bingo Concept Review." Its elements and design principles are listed in Table 2. 
Rules

You will be able to see the questions by clicking on the dollar amount. Please type your answers and your name (at the same time) in the corresponding box below (see example) after clicking on "Edit Wiki Content" tab. Then, remember to click on "submit" tab to complete the editing.

Each student can answer any questions that are not answered by other students. If you answer the question correctly, you will receive the dollar amount for each question. The rank of the participants will be determined by total dollar amount.

Award (6:00 pm CT on March 28, 2016 to 6:00 pm CT on April 1, 2010)

Extra points will be counted toward your exam 1. If you get all possible points on the exam 1, the extra points will be added to your SPSS lab assignments or problem sets.

First place and Second place: 15 points

Third place and Fourth place: 10 points

5 points for everyone who answers at least one question with the correct answer.

\begin{tabular}{|c|c|c|c|c|c|}
\hline $\begin{array}{l}\text { Topic 1: } \\
\text { Confidencelnterval } \\
\text { \&ypots Testing }\end{array}$ & $\begin{array}{c}\text { Topic } 2 \text { : } \\
\text { Correation } \\
\text { and Regression }\end{array}$ & 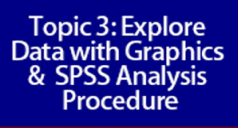 & $\begin{array}{l}\text { Topic 4: Probabability\& } \\
\text { Normal Distribution }\end{array}$ & $\begin{array}{l}\text { Topic5:Intro to Bio\& \& } \\
\text { Descriptive Statisistics (I) }\end{array}$ & $\begin{array}{l}\text { Topic 6: Intro to Bio \& } \\
\text { Descriptive Statistics (II) }\end{array}$ \\
\hline$\$ 100$ & $\$ 100$ & $\$ 100$ & $\$ 100$ & $\$ 100$ & $\$ 100$ \\
\hline$\$ 200$ & $\$ 200$ & $\$ 200$ & $\$ 200$ & $\$ 200$ & $\$ 200$ \\
\hline$\$ 300$ & $\$ 300$ & $\$ 300$ & $\$ 300$ & $\$ 300$ & $\$ 300$ \\
\hline$\$ 400$ & $\$ 400$ & $\$ 400$ & $\$ 400$ & $\$ 400$ & $\$ 400$ \\
\hline$\$ 500$ & $\$ 500$ & $\$ 500$ & $\$ 500$ & $\$ 500$ & $\$ 500$ \\
\hline
\end{tabular}

Jeopardy Exam Review (I)

Created By Cheng-Chia B. Chen on Wednesday, March 9, 2016 4:27:48 AM CST

last modified by 2 Cheng-Chia B. Chen on Wednesday, October 19, 2016 11:23:54 PM CDT

ype your answers and name (at the same time) in the corresponding box.

\begin{tabular}{|c|c|c|c|c|c|}
\hline Topic 1 & Topic 2 & Topic 3 & Topic 4 & Topic 5 & Topic 6 \\
\hline $\begin{array}{l}\$ 100 \\
\text { A confidence interval } \\
\text { estimateis a range of values for } \\
\text { the population parameter with a } \\
\text { level of confidence (c) attached } \\
\text { (e.g., } 95 \% \text { confidence that the } \\
\text { range or interval contains the } \\
\text { parameter). } \\
\text { That is correct!! } \\
\text { Explanation Video }\end{array}$ & $\begin{array}{l}\$ 100 \\
S_{T}=\text { Total variability between } \\
\text { Scores and the mean. } \\
\text { SST }_{T}=\text { Total Sum of Squares. } \\
\text { That is correct!! } \\
\text { Explanation Video }\end{array}$ & $\begin{array}{l}\$ 100 \\
\text { Kurtosis - the measure of } \\
\text { whether data are peaked or flat } \\
\text { relative to a normal distribution. } \\
\text { That is correct!! } \\
\text { Explanation Video }\end{array}$ & $\begin{array}{l}\$ 100 \\
\text { Conditional probability means "the } \\
\text { probability of A under the condition B." } \\
\text { That is correct!! } \\
\text { Explanation Video }\end{array}$ & $\begin{array}{l}100 \\
\text { Biostatistics } \\
\text { That is correct!! } \\
\text { Explanation Video } \\
\end{array}$ & $\begin{array}{l}\$ 100 \\
\text { A small standard deviation } \\
\text { indicates that data points are } \\
\text { close to the mean. } \\
\text { That is correct!! } \\
\text { Explanation Video }\end{array}$ \\
\hline
\end{tabular}

Figure 2. Jeopardy Exam Review Screenshot 1: Demonstration of game rules, mechanics, settings, and wiki tables/cells.

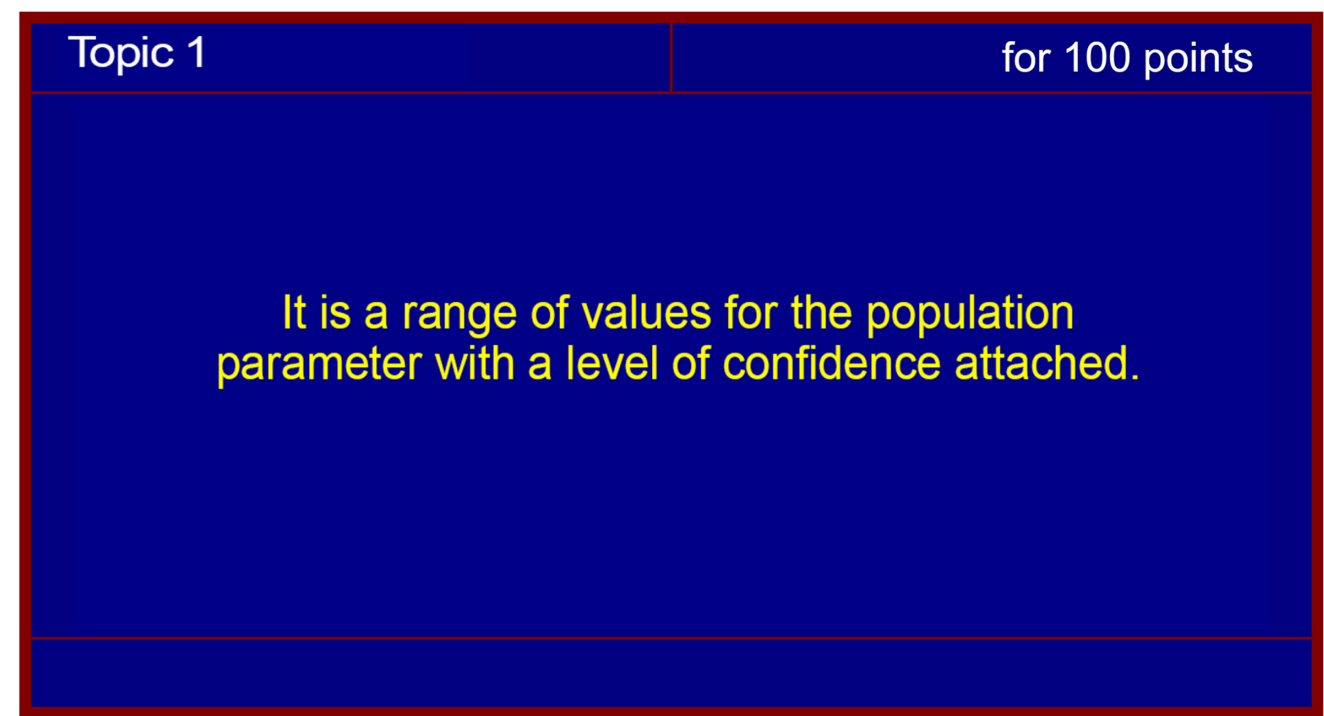

Figure 3. "Jeopardy Exam Review" Screenshot 2: Demonstration question after clicking the dollar sign. 


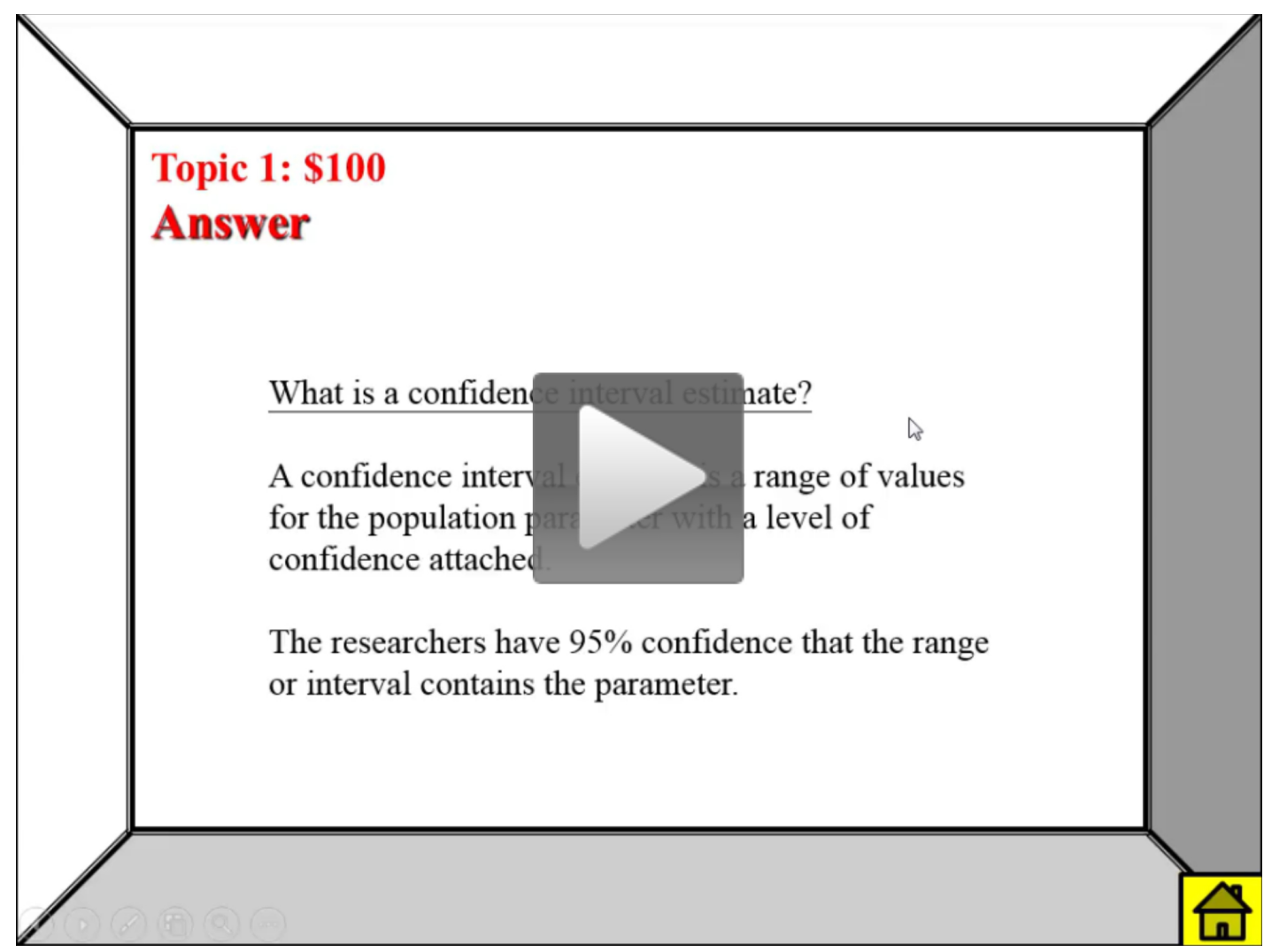

Figure 4. "Jeopardy Exam Review" Screenshot 3: Demonstration of the instructional video that explains detailed solution for the corresponding question. 
Table 2

Online "Jeopardy Exam Review" Gamification Elements and Design Principles

\section{Elements of Gamification for "Jeopardy Exam Review"}

Objectives

Competition \& Challenge

Feedback

Points, Rewards, \&

Leaderboards

Levels

\section{Implementation of the Element \& Design Principle}

The goals to review key statistical concepts for exam preparation.

Students compete to win extra credits and encounter a variety of challenges in the game settings.

The feedback (i.e., detailed answers and/or explanation videos) is given after students have answered all questions (an example of shortened feedback cycles).

This activity gives students the opportunities to earn extra credits.

The rows of questions are ranked from easiest to most difficult, with more difficult answers being worth more points (in the form of dollar values).

Wikis (i.e., a website developed collaboratively by a

Platform

Rules \& Customization community of players, allowing any player to add and edit content).

Game mechanics and adaptive mechanisms to meet the players' skill levels and needs.

Storytelling, Theme, \&

Role-Playing

Replayability
N/A

N/A

\section{Data Collection}

The study participants were graduate students who took an online statistics course across two consecutive academic years (2015-2017) from a midwestern university in the United States. The University of Illinois Webtools (with capabilities similar to Qualtrics) were used to set up online survey questions for the study participants. Two different gamified activities ("Concept Review Bingo" and "Jeopardy Concepts Review") were implemented during fall and spring semesters from fall 2016. "Concept Review Bingo" was played twice for three days while "Jeopardy Concept Review" was played for an entire week during the 16week semester. The participants $(n=80)$ were randomly assigned to the experimental group (i.e., students with exposure to three gamified events) or the control group (i.e., students without exposure to gamification).

There were 44 students in the experimental group and 36 students in the control group. The academic performance of participants in both the experimental and control groups was compared based on the average of the exam scores (midterm and final exams), as was their statistics competency (evaluated by six self-reported questions). In addition, the pre- and posttest design was applied to the experimental group to examine students' perceived usefulness and motivation for statistics before and after the implementation of the gamification. 


\section{Variables and Measurement}

The dependent variables for the present study included academic performance (i.e., the average of all exam scores [maximum 300 points]) and overall statistics competencies. A six-item questionnaire regarding students' statistical competencies with a 5-point Likert scale measurement approach was used. The instrument was inspired by the Master of Public Health (MPH) Core Competency Model initiated and created by the Association of Schools and Programs of Public Health. More specifically, a five-level measure of statistics competency $(0=$ not confident, $1=a$ little confident, 2 = somewhat confident, 3 = highly confident, 4 = extremely confident ) was used. Moreover, several students' perceptions of the usefulness of gamification and selected gamification components (e.g., rules, objectives, competition, and challenge) were surveyed.

\section{Statistical Analysis}

The dependent variable in both the experimental and control groups was academic performance. Since the normality assumptions for parametric analyses in both experimental and control groups were not satisfied, Welch's $t$-test was used to compare the differences between the group mean exam scores. For gamification-related dependent variables in the experimental group that used pre- and posttest experimental design, Wilcoxon tests were used to compare the ranked data from the responses of the Likert-scale survey questions. All data collected were analyzed using IBM SPSS version 24.

\section{Academic Performance}

\section{Results}

A Welch's independent $t$-test was performed to compare the mean exam scores of the control group and experimental group. As predicted, the experimental group $(M=272.40, S D=$ $8.91, n=44)$ had higher scores than the control group $(M=251.44, S D=10.56, n=36), t(68.68)$ $=4.73, p<.001$, two-tailed. This difference favored students who played three different gamified activities to review key concepts (at the .05 level of significance). The results revealed that the experimental group and control group differed in average exam scores. More specifically, students in the experimental group with the implementation of gamification were observed to have higher exam scores, on average, than the control group. The results from Welch's $t$-test can be found in Table 3.

\section{Table 3}

Welch's t-test Between Average Exam Scores From the Experimental and Control Groups

\begin{tabular}{|c|c|c|c|c|c|}
\hline \multirow[b]{3}{*}{ Exam Scores } & \multicolumn{2}{|c|}{$\begin{array}{l}\text { Experimental group with } \\
\text { implementing the games } \\
\qquad(n=44)\end{array}$} & \multicolumn{2}{|c|}{$\begin{array}{l}\text { Control group without } \\
\text { implementing the games } \\
\qquad(n=36)\end{array}$} & \multirow[b]{2}{*}{$t$} \\
\hline & $M$ & $S D$ & $M$ & $S D$ & \\
\hline & 272.40 & 8.91 & 251.44 & 10.56 & $4.73 * * *$ \\
\hline
\end{tabular}

\section{Statistical Competencies}

Statistical competencies were measured by self-report six questions. Table 4 illustrates the results from the comparison of competencies based on the pretest (before the gamification implementation) and posttest data $(n=44)$ using the Wilcoxon test. All measures of statistical competency increased in the posttest group. The Wilcoxon matched pairs signed-rank tests were conducted to determine whether students agreed that their statistical competencies were increased after they used game-playing activities to review the important concepts and to prepare their exams. 
Table 4

Medians and IQR for Pretest Values, Posttest and Difference of Each Statistical Competency

\begin{tabular}{|c|c|c|c|c|c|}
\hline & $\begin{array}{l}\text { Pretest } \\
\text { Median }\end{array}$ & $\begin{array}{l}\text { Pretest } \\
\text { IQR }\end{array}$ & $\begin{array}{l}\text { Posttest } \\
\text { Median }\end{array}$ & $\begin{array}{l}\text { Posttest } \\
\text { IQR }\end{array}$ & $p$ \\
\hline $\begin{array}{l}\text { Discuss biostatistics concepts with } \\
\text { my colleagues and friends }\end{array}$ & 2.00 & 2.00 & 3.00 & 1.00 & $<.001$ \\
\hline $\begin{array}{l}\text { Understand the roles of } \\
\text { biostatistics in research and } \\
\text { program evaluation }\end{array}$ & 2.00 & 1.75 & 3.00 & 1.00 & $<.001$ \\
\hline $\begin{array}{l}\text { Choose the relevant statistical } \\
\text { analyses to answer the research } \\
\text { questions }\end{array}$ & 2.00 & 2.00 & 3.00 & 1.00 & $<.001$ \\
\hline $\begin{array}{l}\text { Make arguments and conclusions } \\
\text { based on proper applications of } \\
\text { analytical approaches with } \\
\text { relevant study designs }\end{array}$ & 2.00 & 1.75 & 3.00 & 2.00 & $<.001$ \\
\hline $\begin{array}{l}\text { Interpret tables, graphs, and } \\
\text { statistical outputs }\end{array}$ & 3.00 & 1.00 & 3.00 & 1.00 & $<.001$ \\
\hline $\begin{array}{l}\text { Make conclusions based on the } \\
\text { statistical results }\end{array}$ & 2.00 & 1.00 & 3.00 & 1.00 & $<.001$ \\
\hline
\end{tabular}

IQR indicates interquartile range.

Note. $P$ values for differences are from Wilcoxon signed-rank test $(n=44)$

${ }^{*} p<.05 .{ }^{* *} p<.01 .{ }^{* * *} p<.001$.

\section{Engagement}

Wilcoxon matched pairs signed-rank tests were conducted to determine whether interest levels were different before and after the exposure of gamified activities. The results indicated that the pretest and posttest medians were not statistically different, as shown in Table $5(p>.05)$.

Table 5

Medians and IQR for Pretest Values, Posttest and Difference of Engagement

\begin{tabular}{|c|c|c|c|c|c|}
\hline & $\begin{array}{l}\text { Pretest } \\
\text { Median }\end{array}$ & $\begin{array}{l}\text { Pretest } \\
\text { IQR }\end{array}$ & $\begin{array}{l}\text { Posttest } \\
\text { Median }\end{array}$ & $\begin{array}{l}\text { Posttest } \\
\text { IQR }\end{array}$ & $p$ \\
\hline $\begin{array}{l}\text { Discussing biostatistics with } \\
\text { colleagues and friend }\end{array}$ & 3.00 & 1.00 & 3.00 & 2.00 & .19 \\
\hline $\begin{array}{l}\text { Exploring public health career } \\
\text { opportunities that require } \\
\text { statistical skills }\end{array}$ & 3.00 & 1.00 & 2.00 & 2.00 & .90 \\
\hline $\begin{array}{l}\text { Reading articles about public } \\
\text { health in journals }\end{array}$ & 3.00 & 1.00 & 3.00 & 1.00 & .16 \\
\hline $\begin{array}{l}\text { Majoring in a biostatistics-related } \\
\text { field }\end{array}$ & 2.00 & 2.00 & 2.00 & 2.00 & .90 \\
\hline $\begin{array}{l}\text { Submitting articles to conferences } \\
\text { or journals }\end{array}$ & 3.00 & 2.75 & 3.00 & 1.00 & .79 \\
\hline
\end{tabular}

IQR indicates interquartile range.

Note. $P$ values for differences are from Wilcoxon signed-rank test $(n=44)$

${ }^{*} p<.05 . * * p<.01 . * * * p<.001$. 


\section{Perceptions of Usefulness, Learning Motivation, and Enjoyment From the Gamified Activities}

We also examined students' perceptions and opinions of gamification at the end of the semester. Seventy-two percent of students agreed that gamified activities were either extremely or highly useful in helping them review and/or understand fundamental concepts. Moreover, $82 \%$ of students stated that it would be worth implementing the competitive educational games to facilitate students' learning in other courses. Sixty-eight percent of students indicated that their learning motivation was higher when competing in the class environment and strongly agreed or agreed that they did better on exams because of what they learned with the games. In addition, $83 \%$ of students strongly agreed or agreed that they enjoyed participating in gamebased learning activities.

\section{Discussion}

Our findings indicated that online gamified activities can have a positive impact on learning statistical and math concepts based on the superior academic performance of the experimental group (i.e., students with the exposure of gamification) compared with the control group. This finding was consistent with several recent studies (DeMarcos et al., 2014; Shatz, 2015; Su \& Cheng, 2015; Yildirim, 2017) that suggested gamification-based teaching practices help enhance students' academic achievement. For the competence concept borrowed from the self-determination theory and the Association of Schools and Programs of Public Health, results indicated that the students had significantly higher confidence in their perceived statistical competencies. This encouraging finding strengthens researchers' assumption that increased confidence in students' statistical competencies might be associated with better academic performance and learning motivation (Ryan et al., 2000).

Interestingly, there was no difference in student engagement when comparing results between experiment and control groups. In other words, online students with gamified activity experience did not increase their perceived engagement. This finding was not consistent with some previous studies that indicated gamification's positive effect on student engagement (Cózar-Gutiérrez \& Sáez-López, 2016; de-Marcos et al., 2017). Although a number of studies found that educational game playing might increase student engagement (Dicheva et al., 2015; Kim et al., 2018), most findings used different measurement methods of engagement that might introduce bias into their results. Moreover, some of their contradictory findings were observed in the traditional on-campus settings instead of online teaching environments.

Furthermore, our study reflects a consistent challenge for educators to transform faceto-face teaching tactics to fit the characteristics and learning needs of online students. Online instructors may need to challenge themselves and employ more instantly interactive gamified learning activities to increase students' engagement. For example, we could use readily available techniques (e.g., mobile apps, chat function in Google Docs to facilitate the effectiveness of collaboration) to expand potential benefits from gamification that might amplify learners' engagement among themselves and between educators and learners.

Several notable findings were observed from the survey results of students' attitudes and perceptions towards their online gamification experiences. Based on our data, a large proportion of students felt that the concept review games were very helpful in strengthening their knowledge of class concepts. In addition, they felt a stronger confidence in their statistical competencies. Moreover, a great number of students mentioned that their learning motivation was higher due to these innovative online gamified activities, and their desire to experience 
similar learning environments was very high. These findings are consistent with previous studies (Barata et al, 2013; de-Marcos et al., 2014).

Although most students were positive about gamification, there were some concerns, such as dislike of the competition atmosphere (i.e., dislike of the first-come, first-choice game rule) and time constraints. Student-centered pedagogy and active learning strategies often tend to consider positive and negative thoughts from students to help them learn better. Thus, the small number of complaints about gamification cannot be neglected; different voices regarding gamification need to be taken seriously (Furdu, Tomozei, \& Kose, 2017). In summary, our findings support our goals to implement meaningful and effective gamified activities to (1) increase students' academic performance and statistical competencies; (2) enhance engagement and social presence among students and instructors; (3) involve every student in an online learning community to review important concepts that students have learned; and (4) help students ease possible frustration from statistics by giving them additional opportunities to review critical concepts through gamification. Our experiences from the creation of online gamification and its influences in self-determined and active learning may provide a new online teaching strategy to enhance students' academic performance and engagement.

\section{Limitations and Future Research Directions}

Though we have learned critical lessons from our findings, the results must be interpreted in light of some limitations. First, students might perceive the researchers' intention to evaluate the effectiveness of the gamification; thus, a certain degree of the Hawthorne effect might have played a minor role in producing a slightly biased outcome. Second, the present study investigated students' perceptions and attitudes toward gamified activities; however, the academic performance aspects that could be influenced by specific gamification attributes (e.g., challenge, goals, and rules) were not individually evaluated. Third, the learning-related influence from gamification was measured in a 16-week course; therefore, the generalizability of findings to any other postsecondary course is limited.

For future studies, a double-blind experimental design could be used to decrease the likelihood of the Hawthorne effect. Researchers could isolate the effects from different gamification components and examine their individual influence on academic performance and students' feedback. Furthermore, cultural influences on effectiveness and acceptance of online gamified learning experiences and settings might be another area to explore.

\section{Conclusions}

The present study was one of the first studies to examine students' academic performance following an innovative application of online gamification from existing LMS collaborative tools. Well-designed gamified activities with proper implementation could enhance online students' academic performance. In addition, students with meticulously planned gamification experiences demonstrated their fondness for these useful games that increased their professional competencies.

These findings may contribute to the existing literature on how gamification-based teaching strategies might play an important role in enhancing online learning effectiveness, increasing students' learning motivation. Moreover, our gamification design that allowed online students to answer questions by co-editing a wiki table had the advantage of taking care of online students' needs for both asynchronous and synchronous learning. Finally, the gamification designs and mechanics that use built-in LMS collaborative tools may help overcome game implementation barriers, such as high game-development costs and the challenge of aligning learning objectives perfectly with existing educational games. 


\section{References}

Association of Schools \& Programs of Public Health. (2018). MPH (master of public health) core competency model. Retrieved from https://www.aspph.org/teach-research/models/mphcompetency-model/

Barata, G., Gama, S., Jorge, J., \& Gonçalves, D. (2013, October). Improving participation and learning with gamification. In Proceedings of the First International Conference on Gameful Design, Research, and Applications (pp. 10-17). ACM.

Cózar-Gutiérrez, R., \& Sáez-López, J. M. (2016). Game-based learning and gamification in initial teacher training in the social sciences: An experiment with MinecraftEdu. International Journal of Educational Technology in Higher Education, 13(1), 2.

Deci, E. L., \& Ryan, R. M. (2008). Self-determination theory: A macrotheory of human motivation, development, and health. Canadian Psychology/Psychologie Canadienne, $49(3), 182$.

Delacre, M., Lakens, D., \& Leys, C. (2017). Why psychologists should by default use Welch's $t$ test instead of student's $t$-test. International Review of Social Psychology, 30(1).

de-Marcos, L., Domínguez, A., Saenz-de-Navarrete, J., \& Pagés, C. (2014). An empirical study comparing gamification and social networking on e-learning. Computers \& Education, $75,82-91$.

de-Marcos, L., Garcia-Cabot, A., \& Garcia-Lopez, E. (2017). Towards the social gamification of e-Learning: A practical experiment. International Journal of Engineering Education, 33(1), 66. Retrieved from https://portal.uah.es/portal/page/portal/epd2_profesores/prof23288/publicaciones/0PaperS ocialGamificationv5.4_IJEE_preprint.pdf

Deterding, S., Dixon, D., Khaled, R., \& Nacke, L. (2011, September). From game design elements to gamefulness: Defining gamification. In Proceedings of the 15th International Academic MindTrek Conference: Envisioning Future Media Environments (pp. 9-15). ACM.

Dicheva, D., Dichev, C., Agre, G., \& Angelova, G. (2015). Gamification in education: A systematic mapping study. Journal of Educational Technology \& Society, 18(3), 75.

Forde, S. F., Mekler, E. D., \& Opwis, K. (2015, October). Informational vs. controlling gamification: A study design. In Proceedings of the 2015 Annual Symposium on Computer-Human Interaction in Play (pp. 517-522). ACM.

Furdu, I., Tomozei, C., \& Kose, U. (2017). Pros and cons gamification and gaming in classroom. Cornell University Library, arXiv.org. Retrieved from https://arxiv.org/ftp/arxiv/papers/1708/1708.09337.pdf

Hamari, J., Koivisto, J., \& Sarsa, H. (2014, January). Does gamification work? A literature review of empirical studies on gamification. In Proceedings from 2014 47th Hawaii International Conference on System Sciences (HICSS) (pp. 3025-3034). Hawaii, United States: IEEE.

Jan, S. L., \& Shieh, G. (2014). Sample size determinations for Welch's test in one-way heteroscedastic ANOVA. British Journal of Mathematical and Statistical Psychology, 67(1), 72-93.

Kapp, K. (2012). The gamification of learning and instruction: Game-based methods and strategies for training and education. San Francisco, CA: Pfeiffer. 
Kappen, D. L., \& Nacke, L. E. (2013, October). The kaleidoscope of effective gamification: Deconstructing gamification in business applications. In Proceedings of the First International Conference on Gameful Design, Research, and Applications (pp. 119-122). ACM.

Leuf, B., \& Cunningham, W. (2001). The wiki way: Quick collaboration on the web. Upper Saddle River, NJ: Addison-Wesley.

O’Donnell, N., Kappen, D. L., Fitz-Walter, Z., Deterding, S., Nacke, L. E., \& Johnson, D. (2017, October). How multidisciplinary is gamification research? Results from a scoping review. In CHI PLAY'17 Extended Abstracts, in Proceedings of the ACM SIGCHI Annual Symposium on Computer-Human Interaction in Play, Parkhuis de Zwijger. Association for Computing Machinery (ACM). Retrieved from http://eprints.whiterose.ac.uk/120652/1/Donnel_Gamification_multidisciplinary.pdf

Rughinis, R. (2013, June). Gamification for productive interaction: Reading and working with the gamification debate in education. In Proceedings of the 8th Iberian Conference on Information Systems and Technologies (CISTI) (pp. 1-5). IEEE.

Ryan, R. M., \& Deci, E. L. (2000). Self-determination theory and the facilitation of intrinsic motivation, social development, and well-being. American Psychologist, 55(1), 68.

Salen, K., \& Zimmerman, E. (2004). Rules of play: Game design fundamentals. Cambridge, MA: MIT Press.

Seaborn, K., \& Fels, D. I. (2015). Gamification in theory and action: A survey. International Journal of Human-Computer Studies, 74, 14-31.

Shatz, I. (2015). Using gamification and gaming in order to promote risk taking in the language learning process. In Proceedings of the 13th Annual MEITAL National Conference, Haifa, Israel (pp. 227-232).

Shi, L., Cristea, A. I., Hadzidedic, S., \& Dervishalidovic, N. (2014, August). Contextual gamification of social interaction-towards increasing motivation in social e-learning. In Proceedings of the 13th International Conference on Web-Based Learning (pp. 116-122). Tallinn, Estonia.

Simões, J., Redondo, R. D., \& Vilas, A. F. (2013). A social gamification framework for a K-6 learning platform. Computers in Human Behavior, 29(2), 345-353.

Urh, M., Vukovic, G., \& Jereb, E. (2015). The model for introduction of gamification into elearning in higher education. Procedia-Social and Behavioral Sciences, 197, 388-397.

Vaibhav, A., \& Gupta, P. (2014, December). Gamification of MOOCs for increasing user engagement. In Proceedings of the MOOC, Innovation and Technology in Education (MITE), 2014 IEEE International Conference (pp. 264-267). Danvers, MA.

Villagrasa, S., Fonseca, D., Redondo, E., \& Duran, J. (2014). Teaching case of gamification and visual technologies for education. Journal of Cases on Information Technology (JCIT), 16(4), 38-57.

Wilson, K. A., Bedwell, W. L., Lazzara, E. H., Salas, E., Burke, C. S., Estock, J. L., ... Conkey, C. (2009). Relationships between game attributes and learning outcomes: Review and research proposals. Simulation \& Gaming, 40(2), 217-266.

Yildirim, I. (2017). The effects of gamification-based teaching practices on student achievement and students' attitudes toward lessons. The Internet and Higher Education, 33, 86-92. 